\title{
Management of Files on Sports Skills of Students with High Level Sports Talents in Normal Universities
}

\author{
Yong Zhang ${ }^{1}$ \\ ${ }^{1}$ College of Foreign Languages Capital Normal University, China
}

Keywords: High Levels, Students With Sports Talents, Normal Universities, Archives, Digitization, Refined.

\begin{abstract}
Based on the explanation of connotation of files on students with high level sports talents in normal universities, this paper analyzes deficiencies and the realistic significance of archive management on these talented students. It also deals with problems in the archive management of students with sports talents from the perspectives of digital management, enhancing management capabilities, enriching contents and exploiting the values of files.
\end{abstract}

\section{Introduction}

Sports students are important members in normal colleges and universities. They are future sports teachers in our country, and the main force in various sports events. The management of files on their sports talents is an important part in students training. These files are professional files, which are formed in the processes of learning and playing in physical education courses and sports competitions.

Through the establishment of archives on students' sports talents, we can make comprehensive records on students' growing, develop scientific management methods on students' files, find out selection and training rules for high level sports students, and eventually achieve the scientific and standardized training and management modes. [1]

\section{The Definition of Files on Sports Skills of Students with High Level Sports Talents in Normal Universities}

The definition of students with sports talents. There is no authoritative definition on talented sports students in high level normal universities and colleges. High level normal sports students in this paper are distinguished from the perspective of archives. They can be divided into two groups. One group includes students who achieved sports honors in high school. They "have the national first-class athlete certificates, or have the national second-class athlete certificates, and won the honor of top eight players in nearly three years in national or international collective sports competition", or "won the honor of top six players in provincial competitions in collective sports projects, or ranked top three in individual events".

The other group includes students who achieved sports honors in normal colleges and universities. They "ranked the top eight in international competitions, or top three in national games, or top six in Asian games; won the title of master sportsman in collective projects or track and field events, or the title of martial hero in martial arts competitions". [2] In addition, potential freshmen can also be included in this group. Sports files on this kind of students have more growth values.

The connotation of files on talented students' sports skills. The establishment of archives on students' sports skills should start from the beginning of their training processes. On one hand, we need to collect archives on students' sports performances from domestic and international sports competitions; on the other hand, we need to find out, collate and analyze files on extremely talented students and establish new archival materials.

The contents of files should include analyses on their sports techniques, training strategies, technical errors, as well as their physical and psychological states in training and competition. 


\section{Classification Methods of Files on Sports Skills of Students with High Level Sports Talents in Normal Colleges and Universities}

Before establishing archives on high level sports students in normal universities and colleges (hereinafter referred to as sports students), we need to determine classification standards first. For files on ordinary students, we should sort out them according to students' specific circumstances, and try to keep the historical continuity of materials.

Classification according to time sequence. General archives are stored according to time sequence, or sports students' ages when they started sports training. According to sports items, age differences in training require the classification according time sequence, for it is conducive to analyses on students' physical conditions and sports skills in different stages. [3]

Classification according to organizations. This is an archiving method according to the training units of students. Some sports students trained in a number of units in different stages, and these original units record their sports performances. The advantage of this classification method is that it can objectively reflect the training situation and development process of sports students in different stages.

Classification according to sports projects. This method adopts the item of sports as classification labels, and archives files on sports students' training, growth and competition performances. This method is convenient for material searching and horizontal comparison.

\section{Deficiencies in Management of Files on Sports Skills of Students with High Level Sports Talents in Normal Colleges and Universities}

Archives on sports students have been established and applied in our country. Files on high level talented students are very helpful for improving the qualities of physical teaching and training. But we also find some shortcomings and problems in the construction and management of archives on skills of high level sports students.

Less awareness on the importance of sports skills. Sports skills occupy the central position in the occupation development of high level students. The formation of high level skills is a development process, which can be reflected in sports archives. Thus, these archives play important roles students' training. In recent years, increasingly financial supports are given to high level sports students. Local government and leaders of sports management departments pay more and more attentions to medals and honors brought by sports students. They do not attach importance to the cultivation of young athletes, or the establishment of archives on high level sports students' skills. Without enough attention, these files which have witnessed the professional development of sports students will gradually be forgotten.

Inadequate hardware investment. File management have basic requirements on hardware. Currently, colleges and universities do not invest enough funds on facility construction and staff training required by file management. The shortage of human, financial and material resources will lead to obstacles in scientific and standardized management of archives. In some provinces, record offices are built in wet, small basements; related facilities are too old to achieve office automation.

Low level of digitization. Digital management is the development trend of archive management. Now the digital technology is widely used in many fields, but archives on skills of sports students are still in the stage of paper files. The management of files on sports students' skills started relatively late in China, and there are many shortcomings in the management mode and security mechanism. Few high level talented students can find archive on their sports skills on Internet. Management departments cannot build up sports database rapidly, so the existing paper records cannot be converted to electronic data. Some established databases are not perfect enough to access Internet. There are many difficulties in the operating, accessing, learning and communicating of archives on skills of sports students. 


\section{Practical Significance of Files on Skills of High Level Talented Students}

Emotional heritage which can mobilize students' training enthusiasm. Emotions are positive factors that affect the mental states of students. Positive emotions can effectively stimulate students' enthusiasm, and ease their nervousness before competition. Sports archives are emotional heritage which witnesses students' growth, records their life experiences are carefully preserves their pasts. It can arouse positive emotions which help students to adjust themselves, and review their professional goals.

Objective bases of scientific training. How to scientifically and accurately select and train potential sports students, is a question which has obvious influences on the continuous improvement of Chinese sports industry. Archives on skills of sports students can meet the practical needs of training. At the same time, archives can reduce the interference of humans' subjective factors when selecting athletes. In addition, according to file contents, trainers can work out more targeted training programs, and have better understandings on students' sports skills. The efficiency of training will be improved.

Realistic samples on the improvement of sports skills. Files on skills of high level sports students detailed record core information like special skills, training strategies, and the formation of core skills. They are rich, vivid models on sports skills. On one hand, through the study and exchange of these materials, coaches and sports students can quickly adjust training methods and improve training efficiencies. On the other hand, when a student analyzes and reviews his/her data, he/she will reflect and find out the way to improve.

\section{Exploration on Management of Files on Skills of High Level Talented Students}

Improving the digital levels of archives management. In the information society, digital archives management is an inevitable trend in archives administration. Improving the digital levels of archives management should not be regarded as innovation in work methods; it is a transformation in management thinking. [4] It can promote the transformation of management on sports skills archives from the perspectives of management concepts and methods, and maximize the opportunities of exchanging and sharing archival information. It is not only helpful for students, but also conducive to digitization of archives on skills of high level sports students.

To improve the digital level of archive management, we need to develop relevant software and optimize the design of file contents. It is also necessary to speed up the construction of sports students' database, and timely update file data to ensure timely and comprehensive information. Then, we need to promote the networking of database on sports files. If sports data cannot be shared and exchanged on the Internet, the digital level of archive management cannot be promoted.

Training high level specialists on archive management. The quality improvement of archive management depends on the professional level of front-line staff. Professional and technical characteristics are outstanding features of archive management work. In order to train high-level archive management specialists, it is necessary to cultivate their excellent occupation morality and good working attitude firstly. Efficiency comes from diligence. Employees need to have high sense of responsibility on file management. Secondly, we need to strengthen the continuous education and training for them. Specialists on archive management need to learn the special characteristics of sports archives, master the skills of digital management, have advanced management concepts and professional abilities. This is an important condition to improve the management of high level sports technical records.

Detailed design on the contents of archives management. With the promotion of sports training levels, students' archives become increasingly complex. Files on sports skills of high level talented students often contain a lot of key information. Therefore, the implementation of delicacy management is conducive to scientific and effective preservation of sports archives.

Traditional sports archives have relatively comprehensive arrangement on basic information. Basic information mainly covers three aspects: one is basic information on the training process of 
individual students, including their training programs, teaching materials, teaching plans, training courses, training summaries and reflections; two is basic information on students' physical fitness tests, personal experiences, skills, and performances in contents; three is information on students' regularly training summaries written by sports management departments. Basic information ensures the complete and standardized sports files.

Delicacy management is not an entirely new system. It means to standardize and group existing archives. [5] We should change the extensive way of overlaying archives on sports students in sequence, and design catalogues including basic information, growth of training techniques, major competition records and other items to sort out files on sports students. Secondly, in view of the existing high-level talented students, the key is to collect data such as their psychological dynamics when they participate in major games, make technical analyses and performance evaluations, set up sports scientific research projects, and comprehensively analyze data of specific skills of high-level talented students.

Scientifically and efficiently excavate the value of archive management. As a kind of historical data, the value of sports files is self-evident. Files on high level sports students are very important, and we need to dig the intrinsic value of them through file management. Firstly, we need to change the concept of work. Sports archives management staffs do not directly engaged in sports, and they believe that their work is to organize and record files. The development of sports students and sports industry is irrelevant with them. Therefore, it is necessary for department leaders and staffs to set up overall conciseness, and understand the significance of sports skills archives. Secondly, we need to attach importance to the exchanging, learning and publicity of high level sports skills files. Under the premise of regulations, these files can go out of the record room for data exchange, and serve more coaches and students. Thirdly, we need to improve the evaluation and incentive mechanisms. From the perspective of system, file management personnel should actively study the contents of files, and enhance the value of sports students in physical education.

\section{References}

[1] Y.G. Li, Technical archive management of students with sports talents, J. Sport Science Research. 4 (1992).

[2] F. Wang, Analyses on the construction and functions of students' archives in physical education colleges, J. Journal of Nanjing Sport Institute. 5 (2008).

[3] R. Chen, The archive management approaches of students with sports talents, J. Lantai World. 29 (2013).

[4] Q.Q. Yan, Information security in digital archives management, J. Shanxi Library Journal. 5 (2009).

[5] M. Chen, Effective methods on archive management of talented students, J. Lantai World. 20 (2006). 